\title{
Effect of a timed interval between inhalation of beta-agonist and corticosteroid aerosols on the control of chronic asthma
}

\author{
MARTIN MUERS, KEITH DAWKINS \\ From the Osler Chest Unit, Churchill Hospital, Oxford
}

ABSTRACT A randomised double-blind crossover study was undertaken in 25 patients with variable airflow obstruction to assess the benefit of separating the inhalation of $\boldsymbol{\beta}$-agonist aerosols and corticosteroid aerosols by a timed interval of more than five minutes. Twenty-two patients (11 men and 11 women) completed 12 weeks of study; they inhaled $200 \mu \mathrm{g}$ salbutamol followed either immediately or after a timed interval by $100 \mu \mathrm{g}$ beclomethasone dipropionate two to four times daily. Morning and evening peak expiratory flow rates, symptom scores, additional $\beta$-agonist inhaler usage, and subjective responses on a visual-analogue scale were recorded throughout. Results from the two last four-week periods, with and without the interval between drugs, were analysed. No differences were found. It is concluded that the theoretical benefit of delaying corticosteroid inhalation until optimum bronchodilatation has been achieved with a $\beta$-agonist is not demonstrable in outpatient practice.

After the demonstration in the 1950 s of the efficacy of oral corticosteroids in treating asthma ${ }^{1}$ attempts were made to develop topical corticosteroid preparations. Micronised hydrocortisone powder was not successful, but after the advent of metered-dose aerosols of beclomethasone dipropionate and betamethasone valerate for use in asthma in the early $1970 \mathrm{~s}^{23}$ many studies have provided evidence that these drugs are safe and effective treatment for asthma with an effect, when used regularly in conventional doses, roughly equal to $5-7 \mathrm{mg}$ of oral prednisolone daily. ${ }^{4-6}$

Many asthmatic patients respond to both $\beta$-agonists and corticosteroids, and combination treatment with separate aerosols of the two types of drugs is common. A theoretical advantage of taking a $\beta$-agonist aerosol several minutes before a corticosteroid aerosol is that rapid bronchodilatation by the former should allow better access of the steroid to the smaller bronchi and therefore make it more effective. There might also be a reduction in any local irritant effect of the steroid aerosol. Although this hypothesis has had no direct proof, intervals

Address for reprint requests: Dr MF Muers, Killingbeck Hospital, Leeds LS14 6UQ.

Accepted 7 January 1983 between drug doses of five minutes or more have been frequently advised. ${ }^{7-11}$ Since spacing the two aerosol treatments widely is inconvenient for patients and compliance with such instructions is likely to be poor, we designed a study of the effect on the control of chronic variable airflow obstruction of both a short and a long interval between inhalations of a $\beta$-agonist (salbutamol) and a corticosteroid (beclomethasone dipropionate) in a group of 25 patients.

\section{Methods}

\section{THE PATIENTS}

Twenty-five patients ( 12 men and 13 women) were recruited from a single adult respiratory diseases outpatient clinic. All patients gave informed consent to the study, which was approved by the local ethics committee. Patients were aged from 18 to 67 years (mean 46.5 years); the mean $\mathrm{FEV}_{\mathrm{i}}$ was $2.41( \pm 0.75$ SD) and the mean FEV /FVC was $63.4 \%$ ( \pm 13.5 SD). All had a history of at least three years of variable airflow obstruction, and had been having combined inhaler treatment for this for at least six months. All patients had a recorded increase in $\mathrm{FEV}_{1}$ after inhalation of bronchodilator of over $15 \%$ at a previous clinic attendance. During two weeks of self-recorded measurement of peak 
expiratory flow rate (PEFR) the mean difference between morning and evening measurements was $12 \cdot 2 \%( \pm 2 \cdot 6 \%)$ and the mean peak diurnal variation was $36 \cdot 2 \%( \pm 23.0 \%)$.

Fourteen patients were atopic, 12 having responded at skin prick testing with a weal over 3 $\mathrm{mm}$ in diameter to one or more of 10 routine allergens (Bencard Ltd), and a further two patients having negative skin prick test responses but a total serum IgE concentration of over $125 \mathrm{U} / \mathrm{ml}$. Eleven patients in all had a serum IgE concentration greater than $125 \mathrm{U} / \mathrm{ml}$. Of the 10 patients with blood eosinophilia $(>500 / \mu \mathrm{l})$, nine were atopic. Two patients were current smokers and five ex-smokers. Of these seven, three were atopic.

No patients were having oral corticosteroid treatment. Eight were taking as additional medication slow-release aminophylline $225 \mathrm{mg}$ twice daily and three of these also took ipratropium bromide 40 $\mu \mathrm{g}$ three times daily by inhalation. The doses of these drugs were constant throughout the study. Thirteen patients took combination inhaler treatment four times daily at entry, three eight hourly, and the remaining nine 12 hourly. These frequencies were not altered during the study.

Before the study 21 patients were taking a $\beta$-agonist aerosol before inhaling the corticosteroid aerosol. Fifteen patients had no appreciable interval between the inhalations; one patient allowed a one-minute interval and four patients a five-minute interval, while one patient waited 15 minutes before inhaling the corticosteroid. Three patients used the aerosols in random order without an interval and one patient took the corticosteroid aerosol before the $\beta$-agonist aerosol, again without an interval. Only one of the 25 patients was using the two types of inhaler in the sequence and with the interval specified routinely in the clinic. Similar discrepancies between prescribed and actual drug usage in adult asthmatic patients have been recorded elsewhere. $^{12}$

\section{TRIAL DESIGN}

The trial was designed as a randomised double-blind within-patient crossover comparison of two drug regimens in which inhalation of a $\beta$-agonist (salbutamol $200 \mu \mathrm{g}$ by pressurised aerosol) was followed by the immediate inhalation of two puffs from the first of a pair of coded identical inhalers. After a fixed, timed interval the patient inhaled two more puffs from the second of the pair of coded inhalers. One inhaler of each pair contained no active drug and the other contained beclomethasone dipropionate $50 \mu \mathrm{g}$ per puff. The pairs of inhalers were allocated randomly and they were given in reverse order after six weeks.
Each patient was provided with a diary card for recording each morning: (1) the frequency of drug administration; (2) symptom score for asthma severity the previous day and night ( 0 -no symptoms/no symptoms, 1-wheezy 1-2 hours/woken once, 2-wheezy most of day/woken 2-3 times, 3wheezy all day/awake most of night); (3) the number of additional inhalations of salbutamol taken during the previous 24 hours for symptomatic relief; (4) any additional medication needed; and (5) the peak expiratory flow rate (best of three attempts) in the morning (on rising, before treatment) and in the evening (at bedtime, before treatment). Wright mini peak-flow meters were used, and technique was checked at the outset of the study.

Patients were seen by the same physician at each clinic attendance, when the inhaler technique was checked, diary cards were collected, and new inhalers were provided. Patients completed a selfassessment of their disease severity during the previous two or four weeks, using a visual-analogue scale with a $10-\mathrm{cm}$ line, ranging from "Asthma never worse" to "Well-no symptoms." The first order of drugs was continued for six weeks with clinic visits at weeks two and six, and then the drug order was reversed and there were clinic visits at weeks eight and 12. For the purpose of analysis, the results from the first two weeks of each period were discarded to minimise any "carry-over" effect between regimens, and therefore the results from the last month of each regimen were compared.

To ensure that the prescribed intervals between the inhalations were adhered to for the duration of the study all patients were issued with simple hourglass timers. Patients were instructed to use these timers whenever the inhalers were used to obtain a constant minimum interval between the two coded inhalers. We used commercially available timers which gave a double-mean time lapse of 7 minutes 36 seconds $(n=18$; range $6 \mathrm{~min} 38 \mathrm{~s}$ to $8 \mathrm{~min} 38 \mathrm{~s}$, SEM $\pm 10.8 \mathrm{~s}$ ). The use of the timers was demonstrated at the start of the trial and their use checked at each follow-up attendance.

\section{STATISTICAL METHODS}

Differences between the results during the two regimens were tested by the Wilcoxon rank sum test for paired samples.

\section{Results}

The results from 22 of the 25 patients who entered the study were available for the final analysis. There were three withdrawals (12\%). All three patients had severe asthmatic exacerbations during the study 
Differences in measures of asthma control between regimens with immediate and delayed inhalations of beclomethasone dipropionate (BDP)

\begin{tabular}{|c|c|c|c|}
\hline & $\begin{array}{l}\text { Immediate } B D P \\
\text { Mean (range } \pm S E M)\end{array}$ & $\begin{array}{l}\text { Delayed } B D P \\
\text { Mean (range } \pm S E M)\end{array}$ & Difference $\dagger$ \\
\hline $\begin{array}{l}\text { Morning PEFR (1/min) } \\
\text { Evening PEFR (1/min) } \\
\text { PEFR diurnal variation (1/min) } \\
\text { Night symptom score/week* } \\
\text { Day symptom score/week }{ }^{*} \\
\text { Additional } \beta \text {-agonist } \\
\text { inhalations/week }\end{array}$ & $\begin{array}{r}290.4(105-514 \pm 24 \cdot 0) \\
307.6(153-528 \pm 23.8) \\
40.3(-11,+88 \pm 5 \cdot 3) \\
2.57(0-8.5 \pm 0.49) \\
4.14(0-9.25 \pm 0.54) \\
10.52(0-50.8 \pm 2.58)\end{array}$ & 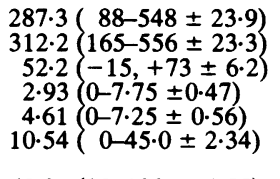 & $\begin{array}{c}3 \cdot 1 \\
4 \cdot 6 \\
11 \cdot 9 \\
0.36 \\
0.47 \\
0.02\end{array}$ \\
\hline Score on visual-analogue scale (mm) & $73.8(7-100 \pm 4.47)$ & $69.0(29-100 \pm 4.55)$ & $4 \cdot 8$ \\
\hline
\end{tabular}

* Scale of 0-3 (0 representing no symptoms) for each day and each night.

†All differences non-significant by the Wilcoxon rank sum test for paired samples.

PEFR-peak expiratory flow rate.

(weeks 2, 8, and 10) and required long courses of prednisolone. At the time of withdrawal one patient was taking beclomethasone immediately after salbutamol and the other two after the timed interval. At entry the characteristics of the three patients were not different in any systematic way from those of the 22 patients who completed the trial.

The differences between the measurements made during the last four weeks of the two treatment periods are shown in the table. There were no significant differences between the two regimens as measured by (1) the night-time and daytime symptom scores; (2) the number of additional puffs of bronchodilator used; (3) the subjective assessments of asthma severity by the visual analogue scale; or (4) either the mean morning peak flow, the mean evening peak flow, or the average difference between the morning and evening peak flows (the diurnal variation).

Although these data provide no evidence for a difference in efficacy between the two regimens for the whole group of patients, we reanalysed the results for the following subgroups of those who completed the trial to see whether a difference was present in a minority of patients: (1) the eight patients who had the highest symptoms scores $(4$ or more per week averaged during either night or day on either regimen); (2) the seven patients whose additional inhaler usage was greater than seven puffs per week; (3) the six patients whose average diurnal peak flow variability before the trial over a two-week period was greater than $15 \%$ (above the group mean level); (4) the 12 patients who at entry were taking the highest dose of beclomethasone (two puffs four times daily).

No significant differences between the two regimens emerged for any of these subgroups.

\section{Discussion}

The result of this study provides no evidence in sup- port of the hypothesis that it is helpful for asthmatics to space out their sequential inhalations of $\beta$-agonists and corticosteroids. There are several possible explanations for this.

Firstly, the design of the study assumed an appreciable difference in the amount of bronchodilatation achieved by the $\beta$-agonist in the interval between inhalation of the "immediate" and the "late" beclomethasone. We calculate that with our regimen the steroid was taken within 30 seconds of the first puff of salbutamol in the "immediate" group and at least seven-and-a-half minutes afterwards on average in the "late" group. Beta-agonist bronchodilators vary in their speed of action, detectable differences being apparent at two minutes. ${ }^{13}$ For salbutamol, it appears from the serial $\mathrm{FEV}_{1}$ measurements reported by Choo-Kang et al, ${ }^{14}$ corrected by an allowance of 75 seconds for the performance of three FEV, manoeuvres (MF Muers, unpublished observations), that only $10 \%$ of the eventual peak change has taken place at 30 seconds compared with $86 \%$ at seven minutes. We therefore conclude that the protocol we used, combined with the use of the timers, should have resulted in a different state of bronchodilatation before the inhalation of beclomethasone in the two parts of the study.

Another possible explanation is that the patients selected were not dependent on their steroid inhalations for asthma control at the time of the study. This seems unlikely. They all showed reversibility of airflow obstruction and had intermittent symptoms. At the outset the group had a low mean $\mathrm{FEV}_{1} / \mathrm{FVC}$ ratio, and despite treatment had a mean diurnal variation in PEFR which was abnormally high. We did not think it practicable or ethical to reduce each patient's beclomethasone treatment in a pretrial period to a level at which a detectable fall in the mean PEFR occurred, but we accept that in other circumstances this might be a satisfactory way of ensuring that alterations in the effective dosage of a given drug (as in our study) would be detectable. 
Thirdly, it is clear that the interval between inhalations is only one of several variables which determine the bronchodilating effect of aerosols in a given patient. Other factors which may alter even during an apparently stable phase are baseline bronchodilatation, ${ }^{1516}$ inhaler technique, and compliance. Although adequate inhaler technique is known to be capable of appreciably improving the bronchodilating effect of aerosols, ${ }^{17}$ even with a standard technique in a given patient (because less than $10 \%$ of administered aerosols penetrates to the tracheobronchial tree ${ }^{18}{ }^{19}$ ) random variations in drug deposition are likely to be large in absolute terms. We think that this variation might provide a "noise" effect against which a small increase in peripheral deposition resulting from previous bronchodilatation would be difficult to detect. Bateman and his colleagues, however, found a $22 \%$ increase in peripheral deposition in a group of asthmatics patients after a bronchodilatation of $13 \%$ of their mean predicted $\mathrm{FEV}_{1}{ }^{20}$

There have been two other studies of the value of combination inhaler treatment in chronic asthma. Clark and Anderson studied 18 patients, 11 of whom were taking oral prednisolone, for two periods of one month, when they received either placebo plus beclomethasone or salbutamol plus beclomethasone. ${ }^{11}$ The inhalations were separated by a 30 -minute interval. They found better control of asthma in all measured parameters while they were taking salbutamol. Bronchodilatation had been shown in all the patients after inhalation of the $\beta$-agonist, and a conclusion drawn from the study is that patients who show this reversibility and who require treatment with beclomethasone derive benefit from this combination treatment. Mackay and Dyson reported a multicentre study in which 36 of $60(60 \%)$ patients completed two consecutive three-month periods of inhaling either $200 \mu \mathrm{g}$ salbutamol 10 minutes before $100 \mu \mathrm{g}$ beclomethasone or the reverse. ${ }^{21}$ These patients showed no difference in the adequacy of asthma control between the two regimens. Thirteen further patients had 19 exacerbations of asthma needing oral steroid treatment during six months of the trial. Eleven exacerbations occurred when the salbutamol was inhaled before beclomethasone and eight during the reverse regimen. The authors concluded that the trial had established no evidence for a preferred order of inhalation. This study did not show directly that immediate inhalation is as efficacious as spaced inhalations. A further difference from the present work is that no method was used to ensure a constant and long period between the drug inhalations throughout the months of the trial. Our own survey showed that most patients prefer to use inhalers in rapid succession, and after our study this was still a majority preference.

From our own study we conclude that an interval between inhalation of $\beta$-agonist and corticosteroid aerosol is not necessary. The studies reviewed above suggest that if patients have been shown to respond to $\beta$-agonists with bronchodilatation before they are treated with corticosteroids these bronchodilator drugs should be continued, ${ }^{11}$ but that the order of aerosol inhalation is not important. ${ }^{21}$ These conclusions are based on studies using pressurised aerosols. It may be beneficial to inhale a bronchodilator drug either immediately before or some minutes before inhalation of a corticosteroid when this is administered in dry powder form.

We would like to thank Dr JM Black, Dr WS Hamilton, Dr DJ Lane and Dr R Marshall for allowing us to study patients under their care. We are grateful to Allen and Hanburys Ltd for the provision of test aerosols and financial support, to Dr JA Faux for the IgE measurements, and to Mrs S Patten for her secretarial assistance.

\section{References}

${ }^{1}$ Medical Research Council Committee on Clinical Trials in Asthma. Controlled trial of the effects of cortisone acetate in chronic asthma. Lancet 1956;ii:798-803.

${ }^{2}$ Morrow Brown H, Storey G, George WHS. Beclomethasone dipropionate: a new steroid aerosol for the treatment of allergic asthma. Br Med J 1972;i:585-90.

${ }^{3}$ Clark TJH. Effect of beclomethasone dipropionate delivered by aerosol in patients with asthma. Lancet 1972;ii:1361-4.

${ }^{4}$ British Thoracic and Tuberculosis Association. A controlled trial of inhaled corticosteroids in patients receiving prednisone tablets for asthma. $\mathrm{Br} J \mathrm{Dis}$ Chest 1976;70:95-103.

${ }^{5}$ Eriksson NE, Lindgren S, Lindholm N. A double-blind comparison of beclomethasone dipropionate aerosol and prednisolone in asthmatic patients. Postgrad Med J 1975;51,suppl 4:67-70.

6 Herxheimer $\mathrm{H}$. Should corticosteroid aerosols be used in severe chronic asthma? Thorax 1981;36:401-3.

${ }^{7}$ Kennedy MCS, Posner E, Thursby-Pelham DC. Longterm treatment of asthma with beclomethasone dipropionate. Postgrad Med J 1975;51, suppl 4:84-6.

${ }^{8}$ Crompton GK. Asthma inhalers: need we be so cautious? Modern Medicine 1977;22:57-8.

9 Empey DW. Asthma. Br Med J 1978;ii:1208-10.

${ }^{10} \mathrm{Gregg}$ I. The importance of patient education in the use of inhaled steroids. In. Mygind N, Clark TJH, eds. Topical steroid treatment for asthma and rhinitis. London: Ballière Tindall, 1980:137-42.

"Clark RA, Anderson PB. Combined therapy with salbutamol and beclomethasone inhalers in chronic asthma. Lancet 1978; ii:70-1.

12 Macfarlane JT, Lane DJ. Irregularities in the use of regular aerosol inhalers. Thorax 1980;35:477-8. 
${ }^{13}$ Paterson IC, Willey RF, Shotter MV, Grant IWB, Crompton GK. Objective and subjective comparisons of terbutaline and rimiterol bronchodilator aerosols. Br J Dis Chest 1975;69:267-72.

${ }^{14}$ Choo-Kang YFK, Simpson WT, Grant IWB. Controlled comparison of the bronchodilator effects of three $\beta$-adrenergic stimulant drugs administered by inhalation to patients with asthma. Br Med J 1969;ii:287-9.

is Altounyan REC. Variation of drug action on airway obstruction in man. Thorax 1964;19:406-15.

${ }^{16}$ Hume KM, Gandevia B. Forced expiratory volume before and after isoprenaline. Thorax 1957;12:276-8.

${ }^{17}$ Newman SP, Pavia D, Clarke SW. Simple instructions for using pressurised aerosol bronchodilators. J R Soc
Med 1980;73:77.6-9.

18 Davies DS. Pharmacokinetics of inhaled substances. Postgrad Med J 1975;51, Suppl 7:69-75.

19 Newman SP, Pavia D, Moren F, Sheahan NF, Clark SW. Deposition of pressurised aerosols in the human respiratory tract. Thorax $1981 ; 36: 52-5$.

${ }^{20}$ Bateman JRM, Agnew JE, Sheahan NF, Pavia D, Clarke SW. Tracheobronchial clearance and ventilatory function after oral corticosteroid therapy in stable asthmatic patients. Thorax 1981;36:226 (abstract).

${ }^{21}$ Mackay AD, Dyson AJ. How important is the sequence of administration of inhaled beclomethasone dipropionate and salbutamol in asthma? $\mathrm{Br} J$ Dis Chest 1981;75:273-6. 